\title{
ARTículo
}

\section{Tradición y modernidad en el uso de los objetos arqueológicos. La frustrada celebración del centenario patrio en el santuario de Pachacamac (1921)}

\author{
Tradition and modernity in the use of archaeological objects. The frustrated \\ celebration of the national centenary in the sanctuary of Pachacamac (1921)
}

\author{
Jhonny Chipana \\ https://orcid.org/0000-0001-7676-5227 \\ ihochiri@gmail.com \\ Universidad Nacional Mayor de San Marcos
}

\begin{abstract}
RESUMEN
Este artículo analiza una experiencia de modernidad del patrimonio cultural prehispánico durante la época del centenario de la independencia nacional, identificando dos propuestas diferentes y contrapuestas sobre su uso, proveniente la primera de una visión tradicional cuyo origen se encuentra en la colonia, y la segunda de las nuevas ideas de la Ilustración, y participando ambas de manera paralela en el ámbito público, la política y la educación. No obstante, ambas propuestas colisionan de manera antagónica en los días de celebración del centenario patrio, a través de los hechos ocurridos en torno al santuario arqueológico de Pachacamac, que finalmente termina saqueada por una de estas dos vertientes.

Palabras clave: Patrimonio cultural; uso de los objetos arqueológicos; excursiones educativas; búsqueda de tesoros; centenario patrio.
\end{abstract}

\section{ABSTRACT}

This article analyzes an experience of modernity of the pre-hispanic cultural heritage during the centenary of national independence. It identifies two different and conflicting proposals on its use: one coming from a traditional vision whose origin is in the colony, and other deriving from the new ideas of the Enlightenment. Both participate simultaneously in the public sphere, politics, and education. However, they collided in an antagonistic way in the days of the celebration of the centenary of the country, through the events that occurred around the archaeological sanctuary of Pachacamac, which finally ended up looted by one of these two aspects.

Keywords: Cultural heritage; use of archaeological objects; educational excursions; treasure hunt; national centenary.

(C) Los autores. Este artículo es publicado por ISHRA, Revista del Instituto Seminario de Historia Rural Andina de la Facultad de Ciencias Sociales de la Universidad Nacional Mayor de San Marcos. Este es un artículo de acceso abierto, distribuido bajo los términos de la licencia Creative Commons Atribución 4.0 Internacional (CC BY 4.0) [https://creativecommons.org/licenses/by/4.0/deed.es] que permite el uso, distribución y reproducción en cualquier medio, siempre que la obra original sea debidamente citada de su fuente original. 


\section{Introducción}

Las celebraciones centenarias han sido siempre motivo de reflexión y evaluación de los diferentes niveles de avance y cumplimiento de la promesa, en este caso de la vida peruana, en sus diversos ámbitos. Esta promesa fue formulada por los libertadores a inicios del siglo XIX, cuando pocas veces como antes hubo un acercamiento auspiciador con nuestro pasado prehispánico, con normas y declaraciones en su defensa, aunque posteriormente olvidadas (Porras, 1974).

Comencemos señalando que el primer uso que tuvieron los objetos prehispánicos en la colonia y que posteriormente se convirtieron en patrimonio cultural fue como botín de guerra en manos de los soldados españoles que lograron conquistar el poderoso imperio incaico, apoderándose de una impresionante fortuna que sirvió, en última instancia, para dinamizar la vida económica mundial a la que nos llevó la metrópoli española. Aunque, en el ámbito local, lo más poderoso fue el nacimiento de muchas ambiciones, con un correlato imaginario de leyendas y fábulas populares que despertaron un apetito peligroso, siendo el más famoso El Dorado que, según la leyenda, era una ciudad completamente de oro, perdida en las montañas y a la cual más de uno entregó su vida en buscarla.

Este uso como botín de guerra, que comenzó a inicios de 1533 en Pachacamac con los objetos que se llevaron a Cajamarca para pagar el rescate de Atahualpa, continuó en los años siguientes por los que detentaban el poder, sea español o criollo, como herederos de un derecho de casta que habían adquirido sus antecesores por las hazañas militares en favor de la corona. Este uso se encontraba amparado legalmente en el Quinto Real, que era un impuesto que tenían que aportar al Rey de España, equivalente a la quinta parte de lo obtenido (Moreyra, 1995). En estas acciones no estaba permitida la participación indígena (Luque, 2012). Sin embargo, debido a necesidades y condiciones socioculturales de la población nativa, que tenía antecedentes en esta práctica, se permitió su intervención en algunas ocasiones, como en el caso conocido del norte del país. Aunque lo más interesante es el alcance que tuvo durante la colonia, con un trabajo organizado y sistemático, formándose compañías buscadoras de tesoros, implementándose funcionarios que supervisaran esta actividad económica y reglamentándose los procedimientos con grandes ventajas para el gobierno real, donde lo más importante era el lucro y la avaricia (Delibes, 2012; Zevallos, 1994).

Aunque desde el siglo XVIII, con la Ilustración y posteriormente con la construcción del Estado nación, comenzaron a adquirir estos objetos una valoración cultural por investigadores, viajeros y coleccionistas, muchos de ellos extranjeros, en realidad no tuvo mayor impacto social, representando una motivación minoritaria y elitista. En la mayoría persistió la idea de que estos objetos servían sobre todo como medio de enriquecimiento fácil, al cual tenía derecho una élite y donde lo más importante no era el esfuerzo, sino el presentimiento, la predestinación, la magia y el azar. Hay que recordar que los cursos de historia peruana en escuelas y universidades nacionales que posibilitaron un acercamiento más extendido al patrimonio cultural solo pudieron implementarse, y de manera tímida, a fines del siglo XIX (Quiroz, 2014).

La independencia nacional y las primeras normas emitidas desde 1822 en favor de la protección del patrimonio cultural prehispánico, no representaron mayor cambio. Continuó la antigua práctica de la búsqueda de tesoros, esta vez con la participación destacada de los grupos militares que habían llegado al poder mediante golpes de Estado, y que sentían que su actitud de entrega y sacrificio a la patria, como antes los conquistadores a la corona, debía ser recompensada por el Estado. Una de estas modalidades era, como venía ocurriendo por tradición desde la 
colonia, apropiándose de los tesoros escondidos, así como también a través de procedimientos legales que las vigentes normas coloniales lo permitían (Gänger, 2018).

Pero no va a ser sino hasta comienzos del siglo XX, después de la dolorosa experiencia de la guerra con Chile y en medio de una expectante bonanza económica, en que gracias a la presencia de nuevos actores sociales procedentes de lo cívico y ciudadano comienzan a introducirse nuevas demandas y ambiciones en este rubro, ya no solo desde la élite investigadora sino desde el ciudadano común, estudiantil, posibilitando la formación de los primeros gérmenes de lo que hoy se llama la cultura patrimonialista en el país, y que va en contrapeso del tradicional uso mercantil de los buscadores de tesoros.

En ese sentido, este trabajo de investigación aborda el tema en cuestión estudiando no a los especialistas en el mismo, como son los arqueólogos, con sus métodos, tendencias y personajes, como en los últimos años se ha realizado (Asensio, 2018; Tantaleán, 2016; Tantaleán y Astuhuamán, 2013), sino más bien desde el ciudadano común, estudiantil, no especialista en el tema, cuya mirada y participación están más cercanas al público promedio, bajo la ventaja de obtener mayores luces de cómo se fueron incorporando estos asuntos en la sociedad. Con ello, se observó no solo los beneficios y posibilidades que ha ofrecido el patrimonio cultural al país, en términos de identidad nacional y construcción de Estado nación, como han concluido dichas investigaciones (Gänger, 2018), sino también se evidenció los otros intereses que iban a contracorriente y contrapuestos a este proceso, y que finalmente le han otorgado un carácter particular a los objetos arqueológicos.

Hay que tener en consideración que los conceptos en favor del patrimonio cultural son construcciones modernas y dinámicas, y que en el tiempo han adquirido otros componentes que al inicio no tenían. Hasta comienzos del siglo XX y durante el periodo que comprende esta investigación, el uso que se le otorgaba desde el Estado era el de instrumento para fines de estudios de la historia peruana, no siendo considerado todavía el actual derecho cultural al disfrute y conocimiento social del pasado, que vendrán décadas después, aunque en los años que comprende este estudio se dan los primeros gérmenes auspiciosos a su favor.

En ese sentido, este artículo que forma parte de un proyecto mayor trata de una experiencia de la modernidad en el uso de los objetos arqueológicos, en un momento coyuntural trascendente en que se van construyendo nuevos derechos culturales que, sin embargo, colisionan con otra fuerza contrapuesta tradicional. Los intereses de esta fuerza pueden ser identificados desde los desenlaces ocurridos en torno a la propuesta de incorporar el santurario arqueológico de Pachacamac a las celebraciones del centenario de la independencia nacional, teniendo en consideración que no solo era la huaca más importante de Lima y de la costa peruana, sino también el lugar del antiguo Perú donde comenzó ese perverso acto de asaltar recintos sagrados en busca de un botín.

Se entiende por modernidad del uso de los objetos prehispánicos al reconocimiento de su valor cultural, útil para el estudio de la historia patria y que pertenece colectivamente a la nación, bajo el cuidado y protección del Estado. Alcanzaba dicho nivel cuando la historia patria, junto a sus objetos, son reconocidos como parte de nuestro pasado, y cuya aproximación corresponde al ámbito del saber y la ciencia, yendo a contracorriente de lo que sucedía hasta ese momento, en que el común de la gente creía que nuestro pasado colectivo procedía de la «historia sagrada» que aún se impartía en las escuelas, utilizando objetos sagrados o «reliquias», y cuyo contacto estaba en el ámbito de la fe. Este es un proceso de desacralización simbólica de lo que hoy 
llamamos patrimonio cultural y cuyo desenlace iba al mismo ritmo con otras experiencias de la modernidad (Muñoz, 2001).

Llevó también un segundo componente fundamental: el derecho a la cultura, en el sentido de disfrute y conocimiento ciudadano de nuestro pasado como un acto democratizador de su uso, tal y como comenzó a suceder progresivamente a comienzos del siglo XX con las excursiones escolares y universitarias que marcaron una diferencia sustancial con lo que sucedía hasta entonces, cuando el interés provenía básicamente de una élite académica. Aunque este derecho a la cultura no era reconocido legalmente en ese momento, sino posteriormente, resulta fundamental en este proceso de modernización, pues representa una forma de intervención, apropiación y control del espacio público constituido por huacas de la ciudad, y que a partir de ahí, comienzan a ser consideradas como un bien común. Hay que tener en consideración que los autores de estos hechos estaban compuestos por ciudadanos comunes, estudiantiles, no especialistas en el tema, que representaban el público promedio de la ciudad, y con los cuales existen mayores ventajas para observar este tipo de experiencias de la modernización.

A contrapartida se encuentra una visión tradicional que consideraba, en su versión original, que los objetos que hoy reconocemos como patrimonio cultural eran bienes privados, de uso comercial y que su más importante valor procedía del natural (minero), al cual tenían derecho los que habían participado en hechos bélicos a favor de una causa estatal, bajo la promesa de una recompensa o derecho. Esto sucedió con los españoles conquistadores y sus descendientes durante la colonia, así como también con los militares y sus aliados que participaron en las guerras civiles de los siglos XIX y XX, utilizando para ello, alternadamente, un permisivo amparo legal o los simples poderes de facto. Se puede distinguir, no obstante, en el tiempo, algunas variantes y matices que podrían compartir por momentos ambas visiones en una ambigüedad sospechosa, y que podrían formar parte también del lento y gradual proceso de modernización que se inicia, con altas y bajas, desde la época de la Ilustración, siendo uno de ellos los hijos ilustres de los saqueadores, conformados por peruanos que gustaban de exhibirse junto a objetos históricos, como los conquistadores con sus tesoros, para obtener esta vez distinción, prestigio y reconocimiento como una casta superior de peruanidad.

Ambas posiciones, sin embargo, se reconocían a sí mismas como portadoras de un superior sentimiento patriótico, con participación destacada en la esfera pública, como sucedió en este caso con ocasión de celebrar el centenario patrio, donde los líderes de ambas tendencias escribieron y publicaron libros en homenaje a la fecha, buscando perpetuarse en el tiempo. Esto ocurrió, por un lado, con Óscar Barros, quien publicó en 1921, junto a Germán Leguía y Martínez, el libro El centenario 1821-1921, y Jorge Corbacho, quien antes había escrito El 28 de julio de 1821, y quien para la ocasión fue nombrado director del museo bolivariano; mientras que, por otro lado, José S. Wagner promovió y prologó el libro oficial de la Municipalidad de Lima con motivo del centenario, bajo el título de Lima en el día del centenario nacional.

Sin embargo, había diferencias que pueden ser identificadas en el origen estamental y de clase de cada una de ellas. Por un lado, estaban los conservadores, vinculados por su procedencia de casta a familias oligarcas, militares y burocráticas; y por el otro lado, los liberales, procedentes de las llamadas profesiones liberales, como el caso de los profesores universitarios, de especialidad nueva (geografía e historia, de reciente incorporación) y que ejercían paralelamente la docencia en las escuelas de media, de inspiración liberal, progresistas y generalmente de procedencia extranjera. Este artículo tiene como problema de investigación los encuentros y resistencias de cada una de estas propuestas, y cómo sus desenlaces podrían generar alguna orientación en la valoración nueva del patrimonio cultural en un momento coyuntural de celebración nacional, 
lo cual quiere decir también la identificación del carácter y naturaleza de esta celebración con respecto al patrimonio arqueológico.

\section{Excursiones de estudio y democratización del uso de los lugares arqueológicos}

Durante la segunda década del siglo pasado, que corresponde al periodo de la llamada República aristocrática, se gestó por primera vez en el país la posibilidad de democratizar los derechos culturales de disfrute y conocimiento de nuestro pasado prehispánico, gracias a las visitas de excursión a dichos monumentos que comenzaron a promoverse desde diferentes niveles gubernamentales. En este proceso destacaron los profesores de nivel universitario y escolar, dando inicio en el país a una nueva práctica de contacto directo con estos lugares que ha tenido sus desniveles en el tiempo, pero que ha sido clave en el proceso de búsqueda participativa de su conservación.

En el caso de los escolares, se dio gracias a dos reglamentos que establecieron la obligatoriedad de estas excursiones, impartidas de manera separada a cada uno de los niveles en que se encontraba dividido el sistema educativo. El primero para las escuelas primarias, aprobado el 28 de julio de 1908 como Reglamento General de Instrucción Primaria (Washburn, 1908); y el segundo para los colegios de nivel medio, el 11 de mayo de 1912, como Reglamento General de Enseñanza Media, Academias y Cursos Libres ${ }^{1}$. Ambos tuvieron muchos años de vigencia.

A partir de ahí, las diferentes huacas de Lima comenzaron a tener un uso y atención que antes no tenían. Ya no eran los recintos exclusivos a los que iban por curiosidad e investigación viajeros extranjeros, con perfil de aventureros, dispuestos a arriesgar y ejecutar excavaciones clandestinas y con beneficio para sus países de origen. Ahora eran niños y jóvenes de instrucción escolar y universitaria, nada especialistas en estos temas, los que viajaban en grandes caravanas, haciendo uso de ferrocarriles, caballos o simplemente a pie, para introducirse a un espacio que recién comenzaba a ser visto como un bien público.

Era el inicio de la modernización del uso de los monumentos prehispánicos, que se dio gracias a la intervención de los profesores de diferente nivel y especialidad como agentes modernizantes, quienes comenzaron a utilizar los monumentos arqueológicos como recurso pedagógico. Esta incursión de los docentes representó a su vez un protagonismo en el espacio público que hasta ese momento no tenían, ejerciendo muchas veces su función en recluidos salones de clase, pero que ahora con este nuevo método educativo les permitía visibilizarse y adquirir un nuevo y reconocido rol ciudadano como formadores de patriotismo en un momento que tanto se necesitaba después de la derrota de la guerra con Chile.

Uno de los protagonistas destacados de esta nueva aventura educativa que llevó a un mayor alcance su papel de agente modernizador fue José Wagner, quien en mayo de 1921, siendo director de uno de los mejores colegios de la capital, y a su vez regidor de la Municipalidad de Lima, propuso al concejo municipal de la capital la «reconstrucción» del santuario arqueológico de Pachacamac, con el objetivo de ser presentado a las delegaciones extranjeras que llegarían con motivo de las celebraciones por el centenario de la independencia nacional. Con este gesto se buscaba extender su uso social que últimamente había venido ganando, dirigido esta vez a eventos internacionales en un momento coyuntural en que muchas naciones intentaban revitalizar sus identidades.

Se trataba de un profesor alemán que había llegado al país hacia 1905, contratado especialmente para acompañar en la dirección del Instituto de Lima al señor Gustavo Bonnet. 1 También publicado en El Peruano, 5 de julio de 1912, p. 33 
Pero debido a la decisión de este último de regresar en 1908 a su país de origen, Bélgica, termina conduciendo directamente el colegio, que tenía para ese momento instrucción elemental, media e internado ${ }^{2}$. Incorpora en su gestión nuevas prácticas educativas procedentes de Europa, como las excursiones escolares a los lugares históricos, que por coincidencia comenzaban a ser promovidas también en el país por el ministerio del ramo.

Una nota periodística de junio de 1919, que reportó una de estas prácticas de Wagner bajo el título de «Las excursiones escolares de Lima» ${ }^{3}$, colocando una amplia fotografía en la portada principal del diario que mostraba a los alumnos del Instituto de Lima en plena acción, dio cuenta de lo frecuente que podrían ser estas excursiones por las huacas de los alrededores de la capital: «llevaba semanalmente a sus alumnos a paseos por los alrededores de Lima» ${ }^{4}$. La nota agregaba asímismo que esas visitas se realizaban con explicaciones del uso y función de cada recinto, según la información disponible, y no faltaban algunas especulaciones o tentativas de aproximación en función a lo que se veía, como sucedió en esta última realizada a las huacas ubicadas entre Magdalena Vieja y Bellavista. ${ }^{5}$

Otro personaje destacado que también incursionó en este nuevo método de enseñanza fue Carlos Wiesse, quien desde 1913 comenzó a sacar a sus alumnos de la Universidad de San Marcos a los diferentes monumentos históricos que todavía existían en Lima. Como lo recuerda uno de sus alumnos más notables, Raúl Porras Barrenechea, quien estudiaba en la Facultad de Letras entre 1912 y 1915 :

Las excursiones universitarias de Wiesse con sus alumnos por los alrededores de Lima, dieron un sentido nuevo y dinámico a la enseñanza, familiarizando a los estudiantes con rincones sugerentes de la ciudad: los viejos conventos, las murallas, el cercado, las huacas Juliana y de Maranga, la quinta de la Perricholi. (Porras, 1963, p. 518-519)

Se trataba, no obstante, de una aventura que tenía sus límites. Era ejercida generalmente en el nivel escolar por las instituciones educativas de tradición liberal, en su mayoría de inspiración extranjera, que eran más afines a esta nueva propuesta promovida por el Ministerio Justicia, Culto e Instrucción. Jugaban un papel fundamental en este proceso, los profesores universitarios que a su vez eran profesores de escuela, quienes venían utilizando desde antes este método con sus alumnos superiores y que ahora lo transmitían con mayor facilidad desde un nivel de instrucción a otro.

Los lugares prehispánicos más visitados en esos años, en las afueras de Lima, eran las huacas Juliana, Maranga, Ancón, Barrios Altos; pero ninguna comparada con Pachacamac, que no solo era el más importante monumento del país ubicado en las afueras de Lima, sino también del que más información se tenía y que en los últimos años había llamado la atención del ámbito académico científico, con importantes publicaciones peruanas y extranjeras, algunas de las cuales fueron producidas por los mismos promotores de las excursiones.

Sin embargo, estaba lejos y distante, separado del valle de Lima por un temido desierto infestado muchas veces por bandoleros. La excursión duraba más de un día y se tenía que pasar la noche en algún lugar cercano a la huaca, que no era comúnmente el mismo lugar agradable que 2 Ilustración Peruana, 3 de febrero de 1910, p. 70-71.

3 La Crónica, 14 de junio de 1919, p. 1, 8.

4 La Crónica, 14 de junio de 1919, p. 1, 8.

5 La Crónica, 14 de junio de 1919, p. 1, 8. 
utilizaban los viajeros extranjeros que llegaban con fines de estudio a la huaca, como era la casa hacienda San Pedro de Lurín, sino más bien un improvisado hospedaje de condición humilde y precario en el valle de Lurín.

Uno de los primeros viajes de este tipo, iniciado la mañana del 15 de junio de 1913 por el profesor Ciro Napanga Agüero, junto a sus alumnos de la Facultad de Ciencias de la Universidad de San Marcos, duró dos días e incluyó pasar la noche en el valle de Lurín. Aunque se trataba de una excursión con una temática más amplia y no exclusivamente arqueológica, en la que estaba incluido el aspecto geográfico del valle y los recientes trabajos de construcción de la vía férrea del tren a Lurín que en esos momentos en encontraba en plena acción, la visita no podía dejar de lado la huaca más importante del valle, la cual era incluso anunciada como uno de los lugares más importantes a reconocer en la nota periodística que la informaba, muy a pesar que el profesor que conducía la misión era doctor en ciencias. ${ }^{6}$

En esa oportunidad, los 40 alumnos que participaron de la excursión utilizaron caballos para toda la travesía, que era el único medio de transporte disponible para llegar a la famosa huaca, que por la distancia lo hacía poco practicable, ocasionando no obstante por su volumen un impacto visual en la rutinaria vida aldeana de la ciudad capital. La partida fue anunciada desde días antes en los medios de comunicación de la época, señalando el horario (8 am.) y el punto de encuentro: la estación del ferrocarril eléctrico a Chorrillos, que era el lugar más equidistante de la ciudad. Se sabía que no era un viaje fácil: se utilizó inicialmente el tren hasta Chorrillos y de allí a caballo por la orilla del mar hasta el valle de Lurín, donde pasaron la noche, y al día siguiente, luego de «visitar las ruinas de Pachacamac»", regresaron a Lima a las 4 pm., empleando esta vez la ruta de la línea férrea en construcción. ${ }^{8}$

Estas excursiones educativas crearon un vínculo más cercano entre los investigadores peruanos, autoridades locales y vecinos del valle de Lurín quienes, hasta ese momento, hasta donde se sabe, poco o o ningún vínculo habían tenido con los viajeros extranjeros que llegaban también al valle con fines de estudio. Posiblemente algunos signos de empatía nacional los hacían más próximos, como sucedió precisamente con la visita del profesor Ciro Napanga y sus alumnos, quienes desde el inicio recibieron las mejores atenciones, siendo esperados en el puente de Lurín por el comisario local, ofreciéndoles las seguridades correspondientes, mientras el alcalde de Lurín les invitaba un banquete con todas las atenciones. Y en la tarde, el alcalde de Pachacamac, Hugo Campbell, hacía lo mismo, conduciéndolos a su hacienda llamada Casa Blanca, donde les ofreció igualmente una comida. ${ }^{9}$

Esta empatía entre compatriotas permitió que se extendiera o democratizara el conocimiento que se tenía hasta ese momento sobre el santuario arqueológico a los pobladores rurales del valle. Uno de estos gestos sucedió con motivo de la visita realizada los días 10 y 11 de julio de 1915 por el historiador Horacio Urteaga y sus alumnos de la Facultad de Letras de la Universidad de San Marcos. Urteaga ofreció, previo a su visita programada a la ciudad sagrada de Pachacamac, una conferencia sobre la huaca a los pobladores de Lurín, en el local municipal del pueblo.

En esa oportunidad fueron 57 alumnos de la Universidad de San Marcos los que llegaron montados a caballo al pueblo de Lurín con el objetivo de pasar la noche en este lugar y luego, al día siguiente, visitar el santuario arqueológico, siendo homenajeados, condecorados y declarados 6 La Prensa, 14 de junio de 1913, p. 2.

7 La Prensa, 17 de junio de 1913, p. 2

8 La Prensa, 15 de junio de 1913, p. 4.

9 La Prensa, 16 de junio de 1913, p. 2. 
huéspedes de honor por las autoridades locales. El profesor Horacio Urteaga devolvió la cortesía con una conferencia en la que estrena los argumentos que había esgrimido en un reciente artículo que había escrito, y que últimamente había sido incorporado a un libro histórico de su autoría. ${ }^{10}$

La actividad se produjo dentro de un ambiente de confraternidad. Los alumnos de la universidad y los vecinos locales se juntaron en una misma sala para escuchar la disertación programada para las 9 de la noche. El profesor habló de la procedencia sagrada de Pachacamac, que probablemente provenía de las divinidades indias, las explicaciones filológicas sobre su nombre, los atributos sobrenaturales que encerraba y, finalmente, el motivo por el cual se eligió este lugar para la erección de su templo sagrado. Después de los aplausos correspondientes, se organizó una fiesta inesperada, donde:

Se bailó, se cantó; a algunos se les subió el vinillo a las sienes y hablaron por doscientos. Un poeta surgió de entre la muchedumbre y alargando el brazo, afiligranado la voz, quejumbroso y romántico, habló de la amada ausente, la amada ideal, a la luz de la luna y qué sabemos cuántas cosas más. Otro quiso hacer un discurso a lo Pérez Zúñiga, se sube al escaño; pero no lo dejan continuar. Que cante, le gritan y él opta por sentarse. Se zarandean unos a otros, pero la soirée pasa en una excelente atmosfera de buen humor, educación y sano compañerismo estudiantil..$^{11}$

Al día siguiente, los excursionistas visitaron por la mañana el santuario arqueológico, acompañado del profesor Urteaga, quien ofreció nuevamente una disertación dirigida esta vez solo a los alumnos, con la ventaja ahora de mostrarles directamente los monumentos con sus argumentos correspondientes, aunque estos fuesen controvertibles: les enseñó la ubicación verdadera del Templo del Sol y del santuario de Pachacamac, que era distinta a lo planteado por Max Uhle, de quien manifestaba se había equivocado, y posteriormente les expuso su planteamiento sobre el origen de ambas edificaciones; finalmente se leyó el libro del padre Cobo correspondiente a la parte que habla de Pachacamac. Antes de regresar disfrutaron de una frugal comida en la misma ciudad sagrada.

Pero el acto más ventajoso en favor de estas excursiones fue la entrada en funcionamiento provisional a partir de 1915 del ferrocarril a Lurín, que venía siendo construido lentamente desde 1912, permitiendo extender a esta parte del sur esta práctica educativa dirigida sobre todo a la instrucción media de la capital que venía saliendo desde meses atrás a los lugares históricos de la capital. Lo mismo venía sucediendo con la huaca Maranga que era visitada con el ferrocarril a la Magdalena; la huaca Aramburu y Concha con el ferrocarril al Callao; la necrópolis de Ancón con el ferrocarril del mismo nombre, así como la huaca Juliana con el ferrocarril a Chorrillos.

Era innegable que había una demanda insatisfecha a favor de Pachacamac y que quedó evidenciada con la entrada en funcionamiento provisional del ferrocarril a Lurín en 1915, produciéndose inmediatamente a su accionar, a pesar de que los rieles pasaban muy lejos de la ciudad sagrada y había que caminar muchos kilómetros para llegar a ella. Esto ocurrió con una de las primeras excursiones realizadas con este fin, el día jueves 14 de octubre de 1915, a cargo de tres instituciones educativas: el Colegio Barros, el Colegio Lima y el Instituto Callao, correspondientes los dos primeros a la capital y el último al primer puerto.

10 La Crónica, 11 de julio de 1915, p. 6.

11 La Crónica, 18 de julio de 1915, p. 7. 
En esa oportunidad, los estudiantes viajaron en tren hasta el último paradero provisional ubicado entonces en Atocongo, a más de 5 kilómetros del objetivo arqueológico, y de allí tuvieron que caminar con mucho esfuerzo en medio de un difícil arenal hasta Pachacamac ${ }^{12}$. Se tenía programada una disertación a campo abierto sobre el santuario a cargo de tres profesores, con una temática diferente, la cual se produjo como era de esperarse después del descanso y refrigerio correspondiente, momento en que además algunos aprovecharon para visitar los diferentes ambientes y lugares del santuario, incluido el templo del Sol, el convento y el palacio. La primera de las instrucciones estuvo a cargo del Dr. Pedro F. Oviedo, quien habló sobre las últimas investigaciones y publicaciones que se habían realizado sobre las ruinas, entre peruanos y extranjeros, así como la religión que practicaban y el prestigio que había adquirido este dios costeño sobre las distintas regiones del antiguo Perú. La segunda estuvo a cargo del Dr. Luis E. Bernales, quien narró las posibles razones de la elección de este lugar para la edificación del santuario, que se encuentra muy cerca al mar, así como de los materiales empleados para su construcción y la presencia de otros grupos étnicos en el lugar. Y la última a cargo del Dr. Enrique D. Tovar, quien explicó sobre la flora característica de la región. ${ }^{13}$

Hay que tener en consideración que esta voluntad de caminar, ida y vuelta, durante muchos kilómetros, sobre territorio ignoto, era posible no solo por su público juvenil, generalmente de mucha vitalidad y entusiasmo, sino también por el naciente espíritu explorador juvenil, de arrojo y valentía, que comenzó a tomar otras dimensiones en esos años. Esta actitud se puede distinguir en las fotografías que fueron publicadas en los periódicos, como sucedió por ejemplo con ocasión de la excursión organizada el domingo 17 de octubre de 1915, también al santuario de Pachacamac, por escolares y universitarios de la capital, utilizando el ferrocarril, y que fue rotulada como «excursión científica» ${ }^{14}$, donde se presentan dos imágenes atiborradas de gente junto a una locomotora y en las mismas «ruinas de Pachacamac» ${ }^{15}$, con una inesperada expresión de entrega.

Sin embargo, aún persistía la idea de peligrosidad sobre el territorio de las afueras de la ciudad, que por muchos años se había constituido en un persistente y malsano miedo social, impidiendo que muchos se atreviesen a salir, generando que, por un lado, este método educativo de salir al campo para instruirse sea acogido lentamente por las escuelas, y por otro, que se formen mecanismos de protección, como sucedió con la participación de los boy scouts, de actitud inicialmente militarista, quienes justamente comenzaron en esos años a implementarse en el país a partir de las escuelas (1912), y que fue de mucha ayuda. Los boy scouts acompañaban sobre todo en las excursiones distantes y apartadas, como era el caso del santuario de Pachacamac.

Es así cómo se puede observar en la excursión organizada el 22 de junio de 1919 al santuario de Pachacamac, por el Instituto Chalaco, que era un colegio de varones de instrucción media que había sido creado en 1902 por el historiador Horacio Urteaga y Augusto Cazorla. Estos personajes participaron en esta visita con su característico atuendo de boy scouts, siendo presentados en unas fotografías publicadas en el periódico La Crónica, a toda página y en contracarátula, en actitud de disciplina, acompañados de unos adultos con distintas vestimentas, a modo de profesores, quienes posiblemente estarían a cargo de la instrucción sobre esta apartada zona arqueológica. ${ }^{16}$

12 La Crónica, 13 de octubre de 1915, p. 04.

13 La Crónica, 16 de octubre de 1915, p. 6.

14 Variedades, 23 de octubre de 1915, p. 2762.

15 Variedades, 23 de octubre de 1915, p. 2762.

16 La Crónica, 24 de junio de 1919, p. 16. 
Sucedió lo mismo con el caso de los colegios de mujeres que también participaron de esta aventura educativa, aunque en menor proporción, como ocurrió el sábado 20 de julio de 1918 con el Liceo Fanning, la más progresista de esos años. Este colegio organizó una excursión instructiva a las ruinas de Pachacamac, con la participación de su «brigada de girl scouts»»", donde el profesor de historia del plantel, el señor Luis A. Rivero, efectuó una disertación histórica sobre este importante lugar, mientras que el teniente Morla, a cargo de las girl scouts, mandó realizar un despliegue de ejercicios físicos.

Todo esto permitió lenta y democráticamente una mayor conciencia del valor del patrimonio arqueológico, donde el contacto directo de los alumnos con los monumentos jugó un papel fundamental. No solo era los inicios de la incorporación de las huacas prehispánicas al currículum y práctica pedagógica nacional, sino también el contagio de estas preocupaciones con los vecinos cercanos a los recintos, gracias a los vínculos que se entablaron.

En ese sentido, se puede decir que los derechos culturales al uso y disfrute de los monumentos arqueológicos por los ciudadanos no especializados en estos temas, como un acto de democratización de su uso, que comienza en este periodo, aunque las leyes todavía no lo contemplaban, provino de la educación y los docentes como agentes de modernización, generando una nueva experiencia moderna del uso arqueológico.

\section{La propuesta reconstructiva de Pachacamac}

La necesidad de intervenir los monumentos prehispánicos con fines de conservación o restauración, es un indicador del nivel de conciencia social en favor del patrimonio cultural. En el pasado no había ese tipo de demandas en el país; se prefería más bien destruirlos por representar manifestaciones paganas o utilizarlos en la búsqueda de tesoros. Ingresar a esta nueva preocupación ciudadana, que forma parte del derecho cultural al disfrute y conocimiento de nuestro pasado, es una manera de modernización del legado histórico.

Como es sabido, en esos años no existían normas peruanas que promovieran la restauración de monumentos históricos, como tampoco el derecho cultural al disfrute del patrimonio arqueológico. Solo se buscaba que no sean destruidos y más bien sirviesen para fines de investigación histórica, como lo señala el decreto de 1893. No obstante, existían algunas preocupaciones sociales en ese sentido, como el proyecto de Ley de 1913 presentado por Emilio Gutiérrez de Quintanilla, donde se planteaba la restauración de monumentos históricos, aunque no llegó a ser aprobada.

Los docentes fueron uno de los impulsores de esta preocupación como agentes de modernización. Ellos acompañaron el pionero trabajo de excursiones educativas, que tuvo mayor incidencia en los alumnos de mayor nivel de instrucción, el medio y universitario. En estas excursiones no solo se explicaba a los alumnos la importancia histórica de cada recinto, sino también la necesidad de conservarlos y mantenerlos para las futuras generaciones.

Uno de estos casos evidentes se dio con ocasión de la visita de excursión realizada el martes 10 de junio de 1913 a la Quinta Presa, más conocida también en esos años como la Casa de la Perricholi, por el profesor Carlos Wiesse y sus alumnos de la Universidad de San Marcos, con el objeto de dar a conocer no solo su valor histórico y artístico, sino también la necesidad de conservarlo:

La casa de la Perricholi es de una arquitectura versallesca; su fachada sus fuentes, sus salones dorados de puestas de luna, bajos y misteriosos; los artesonados, sus 
jardines y baños, todo es un hermoso remedo de las elegantes construcciones del reinado de Luis $\mathrm{XV}$.

La impresión, al contemplar los varios compartimientos de esta casa, es gratísima.

Los gobiernos debían de expropiar estas reliquias históricas y conservarlas como se merecen, ya que es algo de lo muy poco bueno que tenemos. ${ }^{18}$

No fue difícil para los profesores aventurarse en esta nueva proyección, comenzando en este caso con Pachacamac, que era una propuesta de uno de los profesores que venía promoviendo las excursiones escolares y que ahora era regidor de la Municipalidad de Lima, el recordado José Wagner. En pleno preparativo para la celebración del centenario de la independencia nacional, Wagner lanzó en la comuna limeña la iniciativa de restaurar la más importante huaca limeña para presentarla a las delegaciones extranjeras invitadas para la fiesta cívica nacional, abriendo con ello un universo nuevo de posibilidades de uso para los excursionistas.

Se desconoce los detalles de la propuesta de manos de su propio autor. Las referencias que tenemos provienen de otro regidor municipal, Víctor Criado y Tejada, quien secundó la iniciativa con nuevos aportes. Esta propuesta consistía en reconstruir los dos templos más importantes de la ciudad sagrada de Pachacamac: el templo del Sol y el templo de Pachacamac, que eran las edificaciones más sobresalientes y con mayor información en ese momento. Y según sus autores, estos templos habían sido mandados construir por el inca Pachacutec después de la conquista incaica de la costa peruana. Ambos representaban un complemento necesario y contrapuesto: «el Inti [constituía] el templo superior y el de Pachacamac en el inferior, aquel como dios del sol y este como dios del viento y la lluvia». ${ }^{19}$

Se ignora la magnitud y alcance de la obra. Pero en función al presupuesto estimado por las autoridades de la Municipalidad de Lima, se había calculado como cifra total la suma de mil libras de oro; se puede decir que se trataba en realidad de una intervención menor, nada comparable con el monto económico que se había asignado para otros casos, como, por ejemplo, para la compra del edificio recientemente construido, con fines de museo privado y decorado con motivos tiahuanaquenses e incas, por el filántropo Víctor Larco Herrera, en la hoy avenida Alfonso Ugarte de la capital, el cual fue vendido al Estado en 1924, para que sirviera como un museo estatal, por la suma de 100 mil libras peruanas (Ravines, 1996).

Esta situación se condice a su vez con los cálculos de tiempo disponible para la obra, que según las proyecciones no debía durar más de dos meses, ya que tenía que presentarse dentro del programa de celebración por el centenario de la independencia nacional, que estaba ya planificado para fines del mes de julio de 1921. Aunque finalmente las celebraciones conmemorativas se prolongaron hasta gran parte de la década.

Se pensaba que una de las personas que debía asumir la conducción de la obra reconstructora debía ser el Dr. José Kimmich, un filólogo alemán con muchos años de vida en el país, que llegó a ser director del Colegio de Piura y del colegio de Ciencias del Cuzco, y que en esos años venía ofreciendo conferencias y publicando artículos sobre Pachacamac y otras zonas arqueológicas. El Dr. Kimmich planteaba entre otras cosas que el culto al dios Pachacamac tenía un origen japonés, evidenciado según sus explicaciones en seis palabras provenientes de dicha nación oriental que utilizaban los aimaras, y que según su teoría correspondía a uno de los dos grupos étnicos que dominaron en el valle de Lurín.

18 El Comercio, 10 de junio de 1913, p. 2

19 Archivo Histórico de la Municipalidad de Lima. Obra, 1918-1922. Exp. 15. 
Es importante señalar que en esa época no solo se conocía poco del santuario, sino que existían posiciones discrepantes y contrapuestas entre los investigadores. Una de ellas era la ubicación exacta de ambas edificaciones que se pensaba reconstruir. Para algunos, el edificio más elevado e imponente, con mejor vista al mar y que hoy identificamos como el templo del Sol, era en realidad el templo de Pachacamac y viceversa. Ahora sabemos que era un error, pero en esos años no pocos decían lo contrario. Uno de ellos era Horacio Urteaga, profesor de San Marcos, que tenía la ventaja de expresar sus planteamientos en periódicos y revistas de circulación masiva, discrepando sobre este punto con Max Uhle y José Kimmich que decían lo contrario (Urteaga, 1914).

Sin embargo, la elección de Kimmich, que provino del regidor Víctor Tejada y Criado, nos dice de lo precario y artificioso que pudo haber sido esta obra, ya que se trataba de un personaje teórico que posiblemente nunca había realizado antes este tipo de labores y que todo lo que conocía procedía de libros y documentos. Así, corría el peligro que hubiese primado posiblemente la imaginación, los prejuicios y las apariencias, más que la autenticidad y la preocupación por su conservación en el tiempo.

Aunque pudo tratarse también de tan solo un trabajo de limpieza y desentierro, como se sugirió un año después, en marzo de 1922, cuando ante una denuncia hecha sobre Pachacamac, se dijo que la Municipalidad de Lima había botado antes de la celebración del centenario la suma de 10 mil soles para el desentierro de Pachacamac ${ }^{20}$, y se pensaba que:

había ya el propósito de hacer obra científica en el estudio de tales ruinas, pues la municipalidad de Lima había proyectado invertir una fuerte suma de dinero en iniciar el descubrimiento de la ciudad santa, cubierta por las arenas del desierto, como la Esfinge en Egipto y como la antigua Pompeya, revelada hoy intacta. ${ }^{21}$

Pero lo más destacable de la participación del regidor también por Lima, Víctor Tejada y Criado, fue la generosa iniciativa de querer apoyar financieramente con la obra, donando la importante suma de Lp. 500 (libras peruanas), que representaba la mitad del costo de la obra. Este gesto fue aprobado en sesión de concejo del 24 de mayo de 1921, donde se dio cuenta del oficio de Criado y Tejada, «contribuyendo con la suma de Lp. 500 a la reconstrucción de las ruinas de Pachacamac $\rangle^{22}$, pasando subsiguientemente con sus antecedentes a la Inspección de Obras para que formule el presupuesto definitivo.

Lo interesante de este caso es que Criado y Tejada era a su vez también delegado o representante del Concejo Distrital de Pachacamac ante la Municipalidad de Lima. En su carta del 23 de mayo de 1921 en la que ofrecía la donación decía: «como delegado por Pachacamac hago mía esta hermosa iniciativa, ofreciendo contribuir con la suma de cinco mil soles $»^{23}$; lo cual nos puede decir probablemente del nivel de conciencia que habrían alcanzado los vecinos locales del valle en favor de la huaca. No hay que olvidar además que Víctor Tejada y Criado era, al igual que Wagner, miembro del Instituto Histórico del Perú y la Sociedad Geográfica de Lima (Paz Soldán, 1917).

Finalmente, esta propuesta fue considerada como difícil de realizar por la Inspección de Obra, a donde había sido derivada para su evaluación. A través del informe del 3 de junio de 1921, 20 La Crónica, 24 de marzo de 1922, p. 5.

21 La Crónica, 15 de marzo de 1922, p. 9.

22 Archivo Histórico de la Municipalidad de Lima. Libro de actas de sesiones de concejo de la municipalidad provincial de Lima, Libro 2 (1921-1922), fol. 57.

23 Archivo Histórico de la Municipalidad de Lima. Obra, 1918-1922. Exp. 15. 
se argumenta que no había los recursos necesarios disponibles, además del tiempo suficiente para su ejecución, ya que el aniversario se encontraba prácticamente encima, planteando más bien solicitar un subsidio al Superior Gobierno y su aplazamiento transitorio, mientras se formule el presupuesto definitivo. A su vez, el informe calificaba mientras tanto de aceptable la donación formulada por el concejal Criado y Tejada, culminando el expediente el 8 de junio de 1921, cuando se manda transcribir el informe del inspector de Obras al concejal Criado y Tejada.

Es así como la encomiable propuesta de José Wagner, de restaurar Pachacamac en mayo de 1921, fue olvidada en los tristes procedimientos burocráticos, que es una forma de rechazar una iniciativa y que lamentablemente no resulta una novedad en estos ámbitos. No obstante, resulta particularmente interesante identificar y evaluar la experiencia, si tenemos en consideración que se trataba de la única propuesta de intervención en un monumento prehispánico en un momento coyuntural de celebración del centenario patrio.

Lo cierto es que en esos años no había experiencias de ese tipo en el país, siendo una de las primeras la controvertida restauración del Pozo del Inca o Baños del Inca de Cajamarca, en la década de los veinte (Ravines, 2006). Sin embargo, por experiencias extranjeras, y pensando que el caso de Pachacamac era al parecer tan solo uno de limpieza, la propuesta no parecía descabellada. Al menos así lo entendían los funcionarios de la Municipalidad de Lima, que en el informe de evaluación de la propuesta de Pachacamac señalaban que se trataba de un proyecto «bellísimo y digno de aplauso, porque devuelve la finalidad universalmente perseguida de revivir los antiguos usos, costumbres y creencias de los diversos pueblos del globo, dándonos a conocer los detalles de su cultura muchas veces ignorada y que en algunas veces sorprende y admira» ${ }^{24}$, considerando viable este proyecto que seguía «la interesante práctica mundial de reconstruir los monumentos históricos»». ${ }^{25}$

Pero el inconveniente era otro. La Municipalidad de Lima y el Ejecutivo, que iban de la mano, no tenían interés en este tipo de iniciativas. No se trataba tan solo de una visión diferente a la comisión del centenario, que prefería edificaciones monumentales modernas para la ciudad, sin cabida para reconstrucciones prehispánicas, sino también de otros intereses e inclinaciones, más antiguas y profundas, venidos como herencia de la colonia, que colisionaban con estas propuestas reconstructivas e iban de la mano con un decreto recientemente aprobado que promovía la búsqueda de tesoros en lugares históricos, como veremos más adelante.

Esta situación se condice con el hecho de que en ese momento del centenario, las iniciativas más importantes en temas arqueológicos no provenían del Estado, sino de las organizaciones cívicas, privadas y autónomas en un ritmo aventajado, como era el caso del Museo de Víctor Larco Herrera, inaugurado con motivo del centenario en Lima; el Museo Bruning, que comenzó a funcionar de manera privada en Lambayeque desde 1919; el Museo de Arqueología y Antropología de San Marcos, fundado en 1919; y el Museo Arqueológico de la Universidad del Cusco, organizado en 1919 (Ravines, 2006).

El Estado participó de esta celebración con tan solo la habilitación de la antigua casa de los libertadores en la Magdalena Vieja como Museo Bolivariano, el cual fue inaugurado en julio de 1921 como parte del calendario de celebraciones. Para ello, se designó no obstante como director a Jorge Corbacho, presidente de la Asociación de Anticuarios, quien tenía fuertes intereses en la comercialización de objetos históricos y cuya inclinación fue evidenciada en 1922 cuando no se pronunció con motivo del saqueo de Pachacamac, solicitado por los medios, como se verá más 24 Archivo Histórico de la Municipalidad de Lima. Obra, 1918-1922. Exp. 15. 
adelante. Creemos que se trata de un personaje clave, dentro del gobierno de Leguía, para entender las reacciones gubernamentales en contra del patrimonio arqueológico. ¿Era el representante de los anticuarios en el gobierno? (Basadre, 1963).

En ese sentido, mientras los nuevos actores sociales buscaban modernizar el uso arqueológico, tratando ingenuamente de incorporar otras iniciativas como la «restauración» de algunos monumentos prehispánicos, al frente se cocinaban, en contrapartida, otros intereses contrapuestos. Se trataba de una lucha de fuerzas donde no fue suficiente el trabajo educativo de concientización que venían desarrollando los profesores con sus alumnos junto a las comunidades aledañas a las huacas, pues en la otra orilla, en los círculos de poder, donde se deciden las políticas públicas, seguían primando los antiguos conceptos del viejo orden que consideraba a las huacas como lugares para la búsqueda de tesoros.

\section{La reacción conservadora en favor de la búsqueda de tesoros}

Desde comienzos del siglo XX, se fue construyendo en el país, poco a poco, un panorama social más inclusivo en favor del patrimonio cultural, con la participación de nuevos actores sociales organizados e interesados en el tema, en donde el escenario ya no era tan solo algunos dispositivos legales que nadie cumplía, sino diversas organizaciones sociales en actividad. No obstante, esta incorporación generó la reacción incómoda de los grupos imperantes que hasta ese momento de manera ilegal usufructuaban los objetos prehispánicos como tesoros o botines de guerra, en el mismo sentido como venía sucediendo desde la colonia.

Por un lado estaba el Instituto Histórico del Perú y el Museo Nacional, que pertenecían al Estado; y por otro, la Asociación de Anticuarios creada en 1912, la Sociedad Protectora de Bellas Artes y Monumentos Históricos de Lima, fundada en 1911 (Paz Soldán, 1917), los profesores que promovían las excursiones educativas, los propietarios de los museos privados y muchos profesionales independientes que opinaban desde los diversos medios de comunicación, no todos con el mismo interés. Se identificó, no obstante, en este escenario algunos gérmenes del nuevo uso moderno del patrimonio, en el sentido de que estos recursos prehispánicos podrían crear identidad nacional en un momento que tanto se necesitaba después de la dolorosa guerra con Chile, y asimismo como parte de derechos culturales, de conocimiento, uso y disfrute de los monumentos históricos que pertenecen colectivamente a todos, bajo la administración del Estado.

Mientras, por otro lado, estaban los herederos de la tradición huaquera en el país, en sus diversas versiones y matices, quienes veían desde la colonia a estos objetos prehispánicos como propiedad privada, comercializables, obtenidos a través de la búsqueda de tesoros o botines de guerra, con la diferencia que ahora les podrían reconocer algún valor para el estudio de la historia peruana, y en casos más refinados, para obtener prestigio y distinción, exhibiéndose en estas ocasiones junto a sus huacos y demás objetos del pasado para obtener distintivo reconocimiento de peruanidad.

En esta coyuntura se llega a traslucir algunas tramas internas del viejo manejo sobre la forma de pensar y actuar de algunos actores políticos y miembros del Estado, que siempre han existido en el pasado, aunque de manera oculta y en alianza encubierta con terceros, exhibiendo sus intereses, mecanismos de comercialización y formas de obtener derechos sobre los objetos.

Estas situaciones tenían la particularidad de que se presentaban generalmente durante gobiernos autoritarios o dictaduras militares, en los que se reactivaban algunas prácticas antiguas procedentes de una vieja tradición venida de la colonia. Los participantes de los hechos armados que posibilitaron la conquista del poder estatal se creían con el derecho a una recompensa 
con bienes pertenecientes a la nación, siendo uno de estos recursos, en este caso, los objetos prehispánicos que eran utilizados como botines o tesoros. Un ejemplo de ello sucedió en el presente periodo que nos convoca, durante los gobiernos del general Oscar Benavides y Augusto B. Leguía, respectivamente, que llegaron al poder a través de golpes de Estado.

Uno de estos hechos tangibles se dio en el discurso anual de memoria del Ministerio de Justicia, Instrucción, Culto y Beneficencia de 1914, ofrecido al parlamento nacional por el titular del ramo, Luis Julio Menéndez, donde se plantea, al referirse a la reciente separación del Museo de Historia Nacional en dos secciones, una para la colonia y la república y otra para arqueología y antropología, a cargo esta última de Julio C. Tello, la intención de destinarla para comercializar objetos prehispánicos:

Esta última sección se encuentra llamada a adquirir importante desarrollo: porque implantándose un sistema metódico de excavaciones, se podría, dado el interés que han despertado en el mundo nuestras antigüedades incaicas, vender a buen precio las que se obtuvieran, reservando únicamente limitado número de ejemplares de cada una, por cuyo medio, sino llegaran a percibirse ganancias, se haría fácil, por lo menos, organizar paulatinamente, a poco costo, un gran museo en que estuviera cristalizada nuestra civilización primitiva. (Menéndez, 1914. p. XXVII)

Agregando a continuación la necesidad de una Ley al respecto:

Para llegar a tal resultado, se hace necesaria una Ley reguladora de la explotación de nuestros objetos arqueológicos e históricos, pues ellos son hoy base de un comercio devastador, que, invocando los privilegios de la propiedad privada, no tiene escrúpulos de arrancar o devastar páginas de nuestro pasado, para exportarlas al extranjero. (Menéndez, 1914. p. XXVII)

Pero no va a ser hasta el gobierno del presidente Augusto B. Leguía (1919-1930), quien asumiera el poder mediante un golpe de Estado, con la participación de las fuerzas armadas y con prácticas autoritarias durante 11 años, en que se impone esta práctica tradicional de manera legal, emitiendo dos normas al respecto, que buscan en común otorgar a terceros la propiedad de los bienes culturales de la nación.

Es así cómo durante este régimen se emite una norma general sobre el patrimonio cultural de la nación, el Decreto Supremo del 8 de junio de 1921, denominado también «Sobre conservación de los monumentos incaicos ${ }^{26}$, en reemplazo de las dos normas anteriores sobre la materia, el Decreto Supremo del 27 de abril de 1893 y el Decreto Supremo del 19 de agosto de 1911. Con esta nueva norma se regresa nuevamente al régimen de la propiedad privada de los objetos prehispánicos descubiertos, en un acto de retroceso que solo puede ser entendido en función a los beneficiarios de esta norma. Si se hace una comparación con las dos normas anteriores, basada en los dos temas que más preocupaban en la época, como eran el de la propiedad y el de la restricción de exportación de las piezas prehispánicas, se puede decir que: si en la primera, la de 1893, se señalaba que los objetos prehispánicos obtenidos en las excavaciones pertenecen al investigador autorizado, con la libertad de exportarlos, pudiendo el Estado obtener tan solo los objetos duplicados o en su defecto las fotografías de los mismos; en la segunda, la de 1911, se dice que todos los objetos obtenidos pertenecen al Estado, pudiendo otorgarse los duplicados al investigador autorizado, si se trata de una corporación científica de carácter oficial, prohibiéndose

26 La Crónica, 14 de junio de 1921, p. 8. Esta misma norma es también presentada como Decreto Supremo el 11 de junio de 1921 , publicado en El Tiempo, el 14 de junio de 1921, p. 2. 
la exportación de los mismos, con excepción de los duplicados; mientras que en la última, la de 1921, emitida durante el segundo gobierno de Leguía, va en sentido inverso y controvertido, sugiriendo que las piezas obtenidas pertenecen de manera privada al investigador autorizado, ninguna al Estado, aunque con la restricción de no poder ser exportadas, con excepción de los duplicados, pero a título de canje con una institución arqueológica.

Pero la norma más perjudicial y dañina emitida durante este régimen es la Resolución Suprema N. 2068, del 30 de octubre de 1920 (en adelante, Resolución de Tesoros de 1920) del Ministerio de Justicia, Culto e Instrucción, que cristaliza legalmente una vieja ambición de los interesados en estos recursos al abrir la posibilidad de obtener permiso oficial para la búsqueda de tesoros ocultos en lugares históricos. Se trataba de una norma reglamentaria que regulaba este tipo de autorizaciones a terceros para la búsqueda de tesoros en terrenos públicos y privados, sin restricción alguna, pudiendo corresponder a los periodos de la colonia, república o prehispánico. A cambio, el Estado obtenía una parte de los objetos recuperados, distribuidos en una proporción de 1/3 para cada uno de los actores intervinientes: el Estado, propietario del terreno y el denunciante. No existía la obligación de intervenir del Museo Nacional, sino en casos excepcionales, cuando al parecer se trataba de lugares prehispánicos, pero no para llevarse los objetos encontrados con fines museográficos, sino tan solo para realizar vistas fotográficas. En cambio, existía una casi obligatoria participación de la Casa de la Moneda que, como sabemos, tenía una fundición y se encargaba de producir monedas, con el fin de guardar en sus depósitos, en caso de controversia, los objetos descubiertos, donde posiblemente para resolver la controversia se tenían que fundir los objetos metálicos encontrados y distribuir fácil y equitativamente en monedas a los participantes.

Como es de conocimiento, la Casa de la Moneda era una institución que provenía de la colonia y había servido en el pasado para el pago del Quinto Real del Rey cuando se obtenía o descubría algún tesoro prehispánico. Ahora era nuevamente convocado para seguir cumpliendo su viejo papel, como parte de la antigua cadena de saqueo, relegando de esta manera al Museo Nacional que debió reemplazarla como institución republicana en el manejo de los objetos prehispánicos, otorgándoles el valor cultural que tenían y no el comercial, cosa que seguía siendo una deuda pendiente.

Ejerció al parecer un papel fundamental en el planteamiento de esta norma, el señor Oscar Barrós, Ministro de Justicia, Culto e Instrucción, quien además era, para sorpresa nuestra, una persona vinculada con estos temas patrimoniales y que últimamente había suscrito también la Resolución Suprema del 8 de junio de 1921 sobre conservación de los monumentos incaicos. Se trataba de un miembro de la Asociación de Anticuarios e hijo del maestro Pedro M. Barrós, quien tenía un colegio que llevaba su nombre, Colegio Barrós, que en más de una oportunidad llevó a sus alumnos de excursión a lugares históricos como el santuario arqueológico de Pachacamac (Barreto y De la Fuente Chávez, 1926), y ahora aprobaba una resolución que promovía la búsqueda de tesoros en lugares históricos para que sean otorgados mediante autorización por la Dirección General de Instrucción Pública, del Ministerio de Justicia, Culto e Instrucción. ${ }^{27}$

¿Era esta norma una aspiración de la Asociación de Anticuarios? El caso del presidente de esta asociación, constituida en 1912, nos puede dar una respuesta y proyectar algunas luces para entender la trama interna que había por los objetos prehispánicos. Se trataba de Jorge Corbacho, diputado nacional de perfil señorial e interesado en la comercialización de objetos históricos y director del Museo Bolivariano durante el segundo gobierno de Leguía (Paz Soldán, 1917). Corbacho obtuvo repentinamente un poder inusitado gracias a su participación en la salvación de 27 El Peruano, 1 de junio de 1921, p. 1-2. 
la vida y el honor del presidente Leguía. El 29 de mayo de 1909, durante el primer gobierno de Leguía, un grupo de pierolistas intentó ejecutar un golpe de Estado, capturando al mandatario en palacio de gobierno y, tras hacerlo recorrer por las calles de la ciudad, lo obligaron a firmar su renuncia. Leguía pudo ser rescatado a balazos por las fuerzas policiales gracias a la intervención de Jorge Corbacho, quien solicitó valientemente su intervención. Este hecho, que ha sido bautizado como el Día del carácter, dejó más de 100 personas muertas, y en los días siguientes se perpetró una feroz persecución contra sus enemigos políticos (Basadre, 1963). Se trataba de un impedimento de golpe de Estado o un acto valeroso de defensa y retención del poder en peligro, lo cual según la tradición merecía igualmente una recompensa por actos distinguidos, con objetos pertenecientes a la nación, que podía ser por medio de botines de guerra o búsqueda de tesoros.

Se dice que en esa oportunidad Corbacho solo pidió al presidente como recompensa la autorización de poder recolectar documentos históricos en todo el territorio nacional, almacenando durante años una vastísima colección que finalmente logró vender en 1919 a Estados Unidos (Basadre, 1964). Con el regreso de Leguía al poder en 1919 se incorporó esta vez como funcionario del ministerio que emitió la Resolución de Tesoros de 1920.

Se trataba de personas inmersas en el mundo del coleccionismo histórico, que vivían de su comercio y para obtenerlos actuaban muchas veces al margen de la ley, manteniendo algunos de ellos, como Jorge Corbacho, serias diferencias con personajes como Julio C. Tello, quien es considerado como uno de los defensores del patrimonio cultural (Del Castillo y Moscoso, 2002). No obstante, mantenían un reconocimiento por sus conocimientos en el campo de la historia y tenían una activa participación política.

Jorge Corbacho y Oscar Barrós estuvieron vinculados a Leguía, pasando ambos al olvido después de la caída del dictador. Aunque el caso de Barrós fue más violento por sus cercanías al poder. Tras el golpe de Estado de Sánchez Cerro, fue también destituido del último cargo de importancia que había asumido, presidente de la Corte Suprema de Justicia, y nunca más se supo de él.

En ese sentido, se puede pensar que eran ellos los beneficiarios directos de la Resolución de Tesoros de 1920, aunque no los únicos, pues existía ya una red de compra y venta de objetos prehispánicos. Lo novedoso era que ahora los actores de esta actividad, que se estaba volviendo lícita, podían intervenir sobre lugares poco accesibles o citadinos, explotando con mayor libertad uno de los mitos más extendidos sobre la existencia de fabulosos tesoros escondidos en muchos lugares antiguos de la ciudad.

Quizás por este motivo esta resolución fue escondida u ocultada, ya que se conoce de ella no por el documento en sí, sino por sus resultados y efectos. Se ha buscado en libros, periódicos, archivos, sin resultados favorables. Gracias, sin embargo, a las huellas dejadas en el camino, por su uso en diferentes actos administrativos, otorgando autorizaciones a terceros, es que se ha podido identificar sus alcances, intenciones y efectos penosos para el patrimonio cultural de la época.

Uno de los primeros documentos escritos que da cuenta de la existencia de este dispositivo legal ocurre con motivo de la solicitud de aclaración de ella, que formula Enrique de la Riva Agüero, propietario del fundo El Agustino, quien con el ánimo de querer descubrir unos tesoros ocultos que, según se decía, se encontraban enterrados en su unidad agrícola, pide al ministerio alcanzar algunas ventajas, en función a la reciente «Resolución Suprema No. 2068 del 30 de octubre último, destinada a facilitar el descubrimiento de un tesoro»». ${ }^{28}$ 
El resultado de este pedido fue la Resolución Suprema del 20 de noviembre de 1920, publicada en el diario oficial El Peruano, donde se otorga algunas prerrogativas a la parte interesada, en el sentido que: los objetos encontrados que no pudieran ser distribuidos de manera inmediata, y que según el artículo 5 de la Resolución de Tesoros de 1920, deberían pasar provisionalmente a la Casa de Moneda, se resuelva o ejecute de manera más expeditiva, utilizando para este caso lo señalado de manera general en el artículo 4, donde se manda que la distribución se efectúe en tres partes iguales y con equidad entre las partes involucradas. De esta manera, se otorgaba mayor margen de rapidez y distribución, sin la intervención de otros actores e instancias, pues se pensaba que esto podría presentar alguna dificultad.

Un caso preocupante en que se nota la permisibilidad de la Resolución de Tesoros de 1920 y las posibilidades de sacarle la vuelta ocurre con ocasión de la ambiciosa búsqueda de tesoros en el Castillo del Real Felipe que, según la leyenda, contenía fabulosas cantidades de monedas de oro que eran codiciadas por diversas personas, incluido el Estado, ocasionando más de una intervención.

Uno de los primeros personajes conocidos fue Gustavo Hurwitz, quien el 23 de noviembre de 1925, mediante Resolución Suprema No. 540, obtuvo autorización para excavar en el viejo castillo colonial. Pero debido a que «no ha cumplido en ninguna forma con la autorización concedida $\rangle^{29}$, se dejó sin efecto, otorgándose nuevamente, a modo de transferencia, el 26 de diciembre de 1926, al señor F. R. Lanatta, bajo condiciones más ventajosas: la repartición de los objetos encontrados, que se entendía eran monedas antiguas de alto valor, iría en partes iguales entre el señor Lanatta y el Estado, para lo cual se nombrarían unos tasadores, quienes dividirían según el valor que tuviesen actualmente en el mercado cada moneda. Todo ello debía realizarse bajo la condición de que el concesionario se encargase de todos los gastos, dejando al final el lugar en sus condiciones originales e informando diariamente de los avances al Ministerio de Marina. Además, se podía depositar, si fuera el caso, los objetos encontrados en la Casa Nacional de la Moneda, todo en el término de seis meses, que era el tiempo que duraba la concesión. ${ }^{30}$

Es interesante resaltar el concepto de valor histórico que se sugiere en este documento y el tratamiento que recibía. Como se trataba de la búsqueda de dinero o monedas antiguas, posiblemente de la colonia, se expresa implícitamente que no se trataba de objetos de valor histórico, por lo tanto no necesitaba de mayor preocupación o tratamiento; pero en el caso que «los objetos que se descubran y que tengan valor histórico, pasarán a ser propiedad del Estado» ${ }^{31}$, la diferencia se encontraría en el periodo al cual pertenecía. En esos años solo los monumentos y objetos de la época prehispánica se encontraban protegidos legalmente, adquiriendo valor histórico, mientras que los de la colonia y república todavía no alcanzaban esa categoría. Sin embargo, en este documento no se señala los parámetros para identificarlo, como tampoco la autoridad o institución que se encargaría de esta función, abriendo una fisura por la cual los interesados en estos objetos podrían deslizar alguna ventaja o abuso.

No obstante, al parecer, esta concesión no tuvo los resultados previstos en el tiempo esperado, pues el 26 de diciembre de 1927, mediante resolución suprema se renovó la concesión de F.R. Lanatta, y el 3 de febrero de 1928 se nombró a Guillermo Mogrovejo como vigilante de los trabajos que continuaba realizando Lanatta en el Castillo del Real Felipe. Se precisó nuevamente que se encontraban obligados a dar cuenta diariamente de los resultados al Ministerio de Marina. ${ }^{32}$ 29 El Peruano, 10 de enero de 1928, p. 1.

30 El Peruano, 10 de enero de 1928, p. 1.

31 El Peruano, 10 de enero de 1928, p. 1.

32 El Peruano, 18 de febrero de 1928, p. 203. 
Este accionar tenía el perfil de oficial, pues muchas veces participaba el Estado con elementos de seguridad, incluso cuando se trataba de lugares relativamente humildes, como sucedió con la autorización otorgada el 9 de abril de 1927, a través de una resolución suprema, al señor Antonio Molinari, para la búsqueda de tesoros ocultos en una huerta ubicada en el pueblo de Lurigancho, utilizando como fundamento legal, en los considerandos, la controvertida Resolución Suprema del 30 de octubre de 1920, que promovía la búsqueda de tesoros.

En esa oportunidad se conminó a la Prefectura del Departamento de Lima para que dotara de efectivos policiales, garantizando la seguridad correspondiente, además de la designación del Ing. Alberto Madueño como representante del Estado para que acompañara estos trabajos, no pudiendo realizarse ninguna excavación sin su presencia. Se reafirmaba finalmente que lo encontrado sería repartido en partes iguales entre el denunciante, el propietario del terreno y el Estado. ${ }^{33}$

En el diario oficial El Peruano se encuentran publicadas otras resoluciones que tienen el mismo origen, la Resolución de Tesoros de 1920, pero no todos, generalmente los que han atravesado por alguna dificultad, de reclamo, aclaración, exoneración o ventaja. Se podrá tener una mejor idea del impacto de esta resolución cuando se pueda acceder al fondo documental del antiguo Ministerio de Justicia, Culto e Instrucción que custodia el AGN y que ahora no se encuentra disponible al público.

Estos hechos coincidían con la política de gobierno de Leguía, de un doble discurso y con libreto paralelo al oficial, pues por un lado manifestaba su defensa de los monumentos históricos y por otro promovía su destrucción, utilizando para ello el prestigio de algunos intelectuales como Julio C. Tello, a quien incorporó en sus filas e hizo participar «al servicio de los intereses dominantes» (Tantaleán, 2008, p. 41). Con ello, quedaba impedido de denunciar estos hechos que estaban vinculados a amigos muy cercanos a él, como Oscar Barrós, de quien alguna vez consiguió, por su cercanía, beneficios económicos a favor de terceros (Del Castillo y Moscoso, 2002).

Lo cierto es que con esta norma el Estado dejó de ser un actor supuestamente pasivo en esta antigua práctica privada de búsqueda de tesoros, para convertirse en su promotor y socio de los huaqueros modernos. Se podría pensar que, en vista que el Estado se encontraba débil, sin poder defender sus zonas arqueológicas, viendo cómo se llevaban nuestras riquezas, sin poder impedirlo, decidió pasarse al frente, como un actor activo y beneficiarse también de estos saqueos, oficializando esta práctica. Pero no fue así.

Este país que tiene una fuerte predisposición a la vida cortesana y estamental actúa muchas veces en función a prácticas tradicionales, reproduciendo antiguos actos como costumbre más que por nuevos actos deliberados. Y los botines de guerra y búsqueda de tesoros forman parte de una antigua tradición que se viene repitiendo en el tiempo. Lo confirma en este caso el hecho que se siguió manteniendo las antiguas denominaciones procedentes de la colonia: «tesoros»a los objetos arqueológicos y «buscadores de tesoros» a sus perpetradores. Reclama los mismos objetivos: propiedad privada de los objetos, con fines de comercialización, en el mismo sentido que en el pasado con la diferencia que ahora los herederos o hijos de los buscadores de tesoros o botines de guerra se reclamaban peruanos y con sentimiento patrio, otorgándole a los objetos arqueológicos un valor histórico. Los buscadores de tesoro tenían la obligación de respetar las leyes, pero bajo la lectura predominante de la antigua mentalidad, las burlaban, aprovechando 33 El Peruano, 6 de mayo de 1929, p. 440. 
sus vacíos y límites, para seguir apoderándose de los objetos, como sucedió en Pachacamac en 1921-1922, como veremos más adelante.

Es difícil cambiar una antigua tradición que tiene en ejercicio más tiempo que el Estado y la nación peruana, actuando más bien a contracorriente, apropiándose y sometiendo las nuevas leyes republicanas a su mecanismo y control, redefiniendo bajo sus intereses y principios los nuevos conceptos modernos (Trazegnies, 1980). Esta tradición conseguía también que se emitan normas como la Resolución de Tesoros de 1920 que perjudicó el patrimonio arqueológico y con ello la imposibilidad de acercarnos al sueño de los libertadores en favor de la historia prehispánica, y en este caso con la huaca más importante de Lima y la costa peruana, a la que iban en peregrinación los próceres de la independencia en busca de inspiración patria, pero que sin embargo cien años después, en plena celebración del centenario de la independencia nacional, terminó tristemente ultrajada.

\section{Saqueo de Pachacamac en tiempos del centenario (1921-1922).}

Cuando faltaba poco menos de dos meses para el inicio de las celebraciones oficiales del centenario de la independencia nacional, fue publicada en el diario oficial El Peruano una nueva autorización para la búsqueda de tesoros, dirigida esta vez en contra del santuario arqueológico de Pachacamac, la huaca más importante de Lima y la costa peruana, en función a la nociva Resolución Suprema N. ${ }^{\circ} 2068$ del 30 de octubre de 1920 sobre búsqueda de tesoros en lugares históricos.

Se trataba de la Resolución Suprema del 21 de mayo de 1921, publicada el 1 de junio de 1921 en el diario oficial El Peruano, que autorizaba a Enrique Benavides y otros realizar excavaciones en una de las edificaciones más representativas del santuario de Pachacamac, con la descripción siguiente:

Enrique Benavides y otros denuncian la existencia de un tesoro en una de las antiguas fortalezas de los Incas, en las cercanías de Pachacamac, entre las huacas llamadas del Sol, que son de propiedad fiscal, y solicitan que se les reconozcan su carácter de denunciantes y derechos correspondientes. ${ }^{34}$

Era un acto ilegal. En ese momento se encontraba en vigencia el Decreto Supremo del 27 de abril de 1893 y su modificatoria de 1911, que a la letra decía:

Art.1 Se prohíbe hacer exploraciones para buscar objetos arqueológicos, en huacas antiguas, fortalezas, templos u otros pasajes situados en los terrenos públicos o de ninguno, sin una licencia en la forma descrita en el presente decreto.

Art.2 Declárese monumentos nacionales todas las antiguas construcciones anteriores a la conquista que se encuentren dentro del territorio nacional i objeto de interés público su construcción y vigilancia, quedando por consiguiente prohibida la destrucción o inutilización de dichas construcciones. (Mould, 2003, p. 136)

Aademás, los objetos encontrados debían pertenecer todos al Estado, que solo podía conceder los duplicados a la empresa excavadora si esta fuera una corporación científica de carácter oficial. ${ }^{35}$

34 El Peruano, 1 de junio de 1921, pp. 1-2.

35 El Peruano, 02 de setiembre de 1911, p. 1. 
Sin embargo, se pasó por encima de la ley, como otras veces, primando el poderío de una antigua tradición colonial. Un conflicto entre tradición y modernidad, que puede ser entendido también en términos mentales, en el sentido que, en sociedades con una gran carga histórica conservadora, se van formando repúblicas tradicionales, donde las leyes republicanas se acatan en función a la tradición, primando en caso de colisión, la línea que encaja más con esta última opción. Es por eso que se utiliza en este caso como marco legal la Resolución de Tesoros de 1920, que concuerda con su universo mental feudal.

Esta tradición se refleja, asimismo, en la continuidad de un acto administrativo, denominado antiguamente el Quinto del Rey, que era el otorgamiento de la quinta parte de los tesoros descubiertos al Rey de España en tiempos de la colonia, y que era utilizado desde los primeros conquistadores para apoderarse de los objetos prehispánicos como botín de guerra. Y que ahora se pretendía seguir utilizando, aunque con otro marco legal y en una proporción diferente: un tercio a favor del Estado, otro igual al propietario del terreno y otro al denunciante. Y aunque la proporción había variado, continuaba el mismo viejo patrón de distribución, separándose primero lo correspondiente al monarca o autoridad estatal y después a los recurrentes. Como sucedió también en esta oportunidad con el caso de Pachacamac, pues según la resolución antes mencionada de 1921 se mandaba otorgar un tercio al Estado, otro al propietario del terreno y finalmente otro al denunciante. Pero como en este caso el Estado era también propietario del terreno, le correspondía finalmente dos tercios. ${ }^{36}$

Esta situación ventajosa habría ocasionado en este caso que el Estado participe como protagonista principal de este acto lucrativo, estableciendo que esta labor iba «por cuenta del gobierno» y «se proceda a las excavaciones y demás labores conducentes al descubrimiento del tesoro mencionado» ${ }^{37}$. ¿Se habría dado cuenta que se trataba de un buen negocio? ¿Habría otros intereses de por medio a favor de terceros? El Estado intervino en esta oportunidad no solo con personal de vigilancia del Ministerio de Guerra, sino también de Ingeniería Militar, además de la Dirección General de Instrucción del Ministerio de Justicia, Culto e Instrucción, no faltando, asimismo, el director del Museo de Historia Nacional, aunque en un papel indecoroso.

Pero la participación del Estado no era para conservar los objetos prehispánicos con fines de estudio o museográficos, sino todo lo contrario, para honrar el espíritu de la resolución de búsqueda de tesoros, o sea para destinarlo a fines privados y comerciales. Por eso es que nunca se manda que las riquezas y objetos descubiertos pasen al museo, sino tan solo las vistas fotográficas: «De los objetos que se descubran se sacarán fotografías de las cuales se remitirán al Museo Histórico dos ejemplares, por lo menos, autenticados debidamente ${ }^{38}$. Era evidente que el Estado había sido ganado por personajes, hijos o herederos de la tradición saqueadora, que tenían preferencia por esta vieja tradición huaquera, que correspondía en este caso con la norma anterior modificada, el decreto de 1893, que señalaba que los objetos descubiertos pasarían en calidad de propiedad privada a manos del descubridor y que el Estado solo recibiría «las copias fotográficas ... acompañadas de la descripción detallada que baste para dar idea exacta del objeto» (Mould, 2003, p. 136).

Por eso es que la designación de los integrantes de esta misión en Pachacamac tenía un nivel jerárquico, que manifestaba la intención y alcance de este trabajo. Primero, Juan Valles, un desconocido, en calidad de «especialista en la materia», «a cuyas instrucciones se deberán

36 En ese momento estaba en vigencia el Decreto de 1911, que había modificado el anterior Decreto de 1893 y que a la letra decía: «Todos los objetos que se encuentren, pertenecen al Estado» (Mould, 2003, p.92). ; retornando al espíritu moderno y republicano inicial.

37 El Peruano, 1 de junio de 1921, pp. 1-2.

38 El Peruano, 1 de junio de 1921, pp. 1-2. 
efectuarse los trabajos de descubrimiento ${ }^{39}$ ¿Experto en descubrir tesoros?; y en segundo lugar, el director del Museo de Historia Nacional, en calidad de «asistente». Un desequilibrio que revela su triste finalidad.

Todos estos actos confirman que había una reacción de inconformidad de los hijos de los saqueadores en contra de la modificación del Decreto Supremo de 1893, ocurrido en 1911, pues con ello se le quita a los descubridores de los objetos arqueológicos el privilegio de hacerse propietarios de estos materiales. El deseo de estos saqueadores era regresar al escenario anterior, que solo se consigue durante el gobierno de Leguía, con la promulagión de la Resolución de Tesoros de 1920 y la resolución de conservación de monumentos incaicos de 1921, que les restituye ese viejo privilegio de propietarios de los objetos descubiertos.

En ese sentido, se trataba de una sacada de vuelta a la ley. Es curioso observar que en ninguna de las resoluciones que aprobaba autorizaciones sobre búsqueda de tesoros publicadas en El Peruano se menciona, en los considerandos, las normas de protección del patrimonio, el Decreto de 1893, su modificación de 1911 o el nuevo Decreto de 1921; pero en cambio siempre se menciona sin excepción la Resolución de Tesoros 1920, lo cual quiere decir que los hijos de los saqueadores de tesoros conocían la legislación sobre la materia, pero solo «invocaban» la que les convenía. O sea, no era desconocimiento, sino astucia deliberada, que tenía la intención de seguir continuando con esta tradición lucrativa por cualquier medio.

Sin embargo, esta intención de saqueo en Pachacamac no fue inmediata. Al parecer hubo un impase o reclamo después de la publicación de la autorización, ocurrida el 1 de junio, pues días después fue aprobado el Decreto Supremo del 8 de junio de 1921, denominado también Sobre conservación de los monumentos incaicos, donde se reafirma nuevamente la voluntad del gobierno de proteger los monumentos arqueológicos, como un acto posible de reacción o aclaración ${ }^{40}$. Lo cierto es que tuvieron que pasar muchos meses para que se ejecute la autorización.

Hasta que fue el miércoles 15 de marzo de 1922, día en que la ciudad de Lima amaneció con la increíble noticia de que el santuario de Pachacamac venía siendo saqueada. El diario $L a$ Crónica fue la primera en dar la voz de alarma, presentando en su portada como prueba del delito dos grandes fotografías que contenían la imagen de cuatro carpas de campaña de un grupo de militares asentados en la misma zona arqueológica, bajo la nota: «soldados del ejército están destruyendo desde hace veinte días». ${ }^{41}$

Los titulares periodísticos de esos días fueron: Destrucción de las ruinas de Pachacamac, Bárbaro atentado de Pachacámac, Crimen de lesa civilización. Se están destruyendo las ruinas prehispánicas de Pachacamac. Pero no todos los medios periodísticos de la época se sumaron a la campaña, que en esos años era más de diez. Muchos se quedaron en silencio. Solo La Crónica, El Tiempo y la revista Variedades se ganaron el pleito.

Lo mismo sucedió con las instituciones que decían abogar por estos temas, como el Instituto Histórico del Perú, la Sociedad de Anticuarios del Perú, que tampoco se manifestaron, a pesar de que en esos días los medios periodísticos reclamaban su pronunciamiento. ${ }^{42}$

39 El Peruano, 1 de junio de 1921, pp. 1-2.

40 El Peruano, 17 de junio de 1921, p. 687.

41 La Crónica, 15 de marzo de 1922, p. 8

42 La Crónica, 15 de marzo de 1922, p. 9. 
Se decía que esta operación tenía licencia otorgada a «un caballero vinculado con una conocida familia de Lima» ${ }^{43}$, y que venía siendo ejecutada física y directamente desde hace más de 20 días (otras versiones señalaban dos meses) por miembros del Ministerio de Guerra, quienes instalados en unas carpas y haciendo uso de un decauville, que es un pequeño trencito con rieles para facilitar el movimiento de tierras, venían excavando y destruyendo muros, tumbas, lienzos, entre otros. Bajo una planificación militar, intervenían periódicamente y por turnos, soldados del Regimiento N. ${ }^{\circ} 19$ y N. ${ }^{\circ}$ 21, a cargo del jefe del destacamento, el mayor Bueno y el teniente Sarmiento.

Por eso es que la acusación fue contra el Estado, representado por el Ministerio de Justicia e Instrucción y el Ministerio de Guerra, respectivamente, directamente implicados, cuyos funcionarios decidieron más bien guardar silencio. Posteriormente se dio a conocer a través de un funcionario de menor rango que la única acción mandada a ejecutar por el primero contra el segundo implicado era el de pedir un informe detallado de los acontecimientos y objetos descubiertos. Pero sin paralizar la obra. ${ }^{44}$

Al parecer había muchos intereses y ambiciones en juego. No querían suspender la obra. Se decía que quien dirigía el trabajo «estaba en posesión de un secreto, por el que se llegaba al sitio donde se ocultaba el gran tesoro que los indios ocultaron de la rapacidad de los españoles» ${ }^{45}$, allá por el siglo XVI, cuando ante la llegada de Hernando Pizarro a Pachacamac para obtener el rescate de Atahualpa, los sacerdotes decidieron enterrar por ahí cerca los mejores objetos de metal. Y que ahora un personaje autorizado conocía el secreto donde se hallaría, según se decía, «planchas de oro», la «puerta de plata del santuario», «llamas de oro que adornaban el palacio del curaca ${ }^{46}$, entre otros.

El 19 de marzo de 1922 viajó a Pachacamac una delegación de periodistas para observar directamente los hechos y recoger información que permitiera continuar con las denuncias, bajo el liderazgo de Clemente Palma, a la sazón diputado nacional por Lima y director de La Crónica, así como del profesor José Wagner, que venía ejecutando en esos días excursiones escolares por las huacas de Lima. Pero esto no fue suficiente para paralizar la obra. Tres días después, el Ministerio de Guerra envió otro contingente de soldados para continuar con el saqueo. ${ }^{47}$

En esos días salieron varias caricaturas e historietas para graficar la desazón, pero la más esclarecedora sobre el caso fue la publicada como portada en la revista Variedades del 8 de abril de 1922, donde aparece un huaco retrato con el rostro al parecer del Ministro de Justicia, Culto e Instrucción, que a su vez era miembro de la Asociación de Anticuarios, con la leyenda: «DE PACHACAMAC / un huaco sacado de las ruinas de Pachacamac: no tiene valor alguno el histórico no más» ${ }^{48}$. Una ironía que invierte las declaraciones dadas en esos días al parecer por el ministro en contra de él mismo, con referencia a lo encontrado en Pachacamac, en el sentido que los objetos encontrados no tendrían valor económico, solo histórico.

Así es como, durante los días de celebración del centenario de la independencia nacional, en que se evocaba la liberación de España con inauguraciones, ceremonias y desfiles, a treinta kilómetros de la capital, la huaca más importante de Lima y de la costa peruana, donde los

\footnotetext{
43 La Crónica, 15 de marzo de 1922, p. 9.

44 La Crónica, 19 de marzo de 1922, p. 2.

45 La Crónica, 15 de marzo de 1922, p. 9.

46 La Crónica, 15 de marzo de 1922, p. 9.

47 La Crónica, 24 de marzo de 1922, p. 05.

48 Variedades, 08 de abril de 1922.
} 
españoles habían iniciado en el pasado el saqueo de las riquezas prehispánicas con el rescate de Atahualpa, volvía nuevamente a transitar por otra hazaña semejante de saqueo y destrucción. Esta vez, el saqueo era perpetrado por un grupo de peruanos, hijos descendientes de los antiguos saqueadores, mostrándonos que no habíamos cambiado mucho cien años después y que todavía necesitábamos emanciparnos de algunas tradiciones perniciosas del viejo orden.

\section{Conclusiones}

Desde inicios del siglo XX, comenzó a formarse un movimiento en favor del patrimonio arqueológico por parte de ciudadanos comunes, estudiantiles, no especializados en esta disciplina, quienes comenzaron a organizar y participar en excursiones escolares y universitarias a las huacas de la ciudad de Lima, provocando que se formase una conciencia en su defensa, donde el contacto directo con dichos monumentos fue clave. Ellos consiguieron que estos lugares abandonados comenzaran a ser vistos y considerados como un bien público y como parte de los espacios públicos de la ciudad, al cual cualquier persona interesada en el tema podría ir de visita.

Se trataba de una forma de modernización de los monumentos y objetos arqueológicos, que a partir de ahí comenzaron a ser considerados, por el común de los ciudadanos, como parte de nuestra historia colectiva y patriótica, que necesitaba ser estudiada y cuyo acercamiento formaba parte del ámbito del saber y la ciencia. Ello iba a contracorriente de la visión tradicional, que señalaba que nuestra historia colectiva procedía de la «historia sagrada» que aún se impartía en las escuelas como un curso obligatorio, el mismo que hacía uso de objetos de veneración o «reliquias» que correspondían al ámbito de la fe. A su vez, esta última posición consideraba, en su versión más antigua, que era acertado el saqueo y la búsqueda de tesoros prehispánicos, pues iba en contra del paganismo, proceso que permitió finalmente la desacralización de los objetos de nuestra historia colectiva y nacional.

Fueron protagonistas principales de este proceso los docentes de escuelas y universidades, quienes, como agentes de modernización, comenzaron a utilizar los monumentos arqueológicos como recurso pedagógico, permitiendo que este acercamiento con los alumnos significara un acto de democratización de su uso y a su vez la incorporación de nuevos derechos culturales. El propósito más avanzado de esta propuesta educativa era restaurar la huaca más importante de Lima y la costa peruana, Pachacamac, con el objetivo de ser mostrada a las delegaciones internacionales que vendrían con ocasión de la celebración del centenario patrio. Pero que, sin embargo, fue impedido por una reacción contrapuesta.

Paralelamente a esta fuerza de cambio, existía desde la colonia un uso tradicional de estos mismos objetos, que en su versión original consideraba que eran botines de guerra, con fines privados y mercantiles, pero que posteriormente con la Ilustración y el naciente Estado nación fueron adquiriendo poco a poco algunas valoraciones culturales, aunque sus usuarios, hijos simbólicos de los antiguos saqueadores prehispánicos, siguieron apostando por un uso lucrativo y comercial. En los últimos años, con motivo de la presencia de nuevos actores sociales modernizantes y en actitud de reacción, lograron nuevas posiciones, incorporándose en puestos claves dentro del gobierno de Augusto B. Leguía y desde ahí conseguir nuevas ventajas legales en favor de la búsqueda de tesoros, destruyendo con ello muchos lugares históricos, entre ellos, Pachacamac, eclipsando de esta manera la posibilidad de incorporar este santurario a las celebraciones del centenario nacional.

Se trataba de un choque de fuerzas que provocó que los protagonistas tradicionales con mayores ventajas tuvieran que reformularse en el escenario nacional con nuevas estrategias. Se puede identificar entre ellos actitudes sospechosamente ambiguas y tendenciosas con relación a 
los objetos arqueológicos, donde algunos personajes podrían actuar, al mismo tiempo, en defensa de la patria y celebrar la búsqueda de tesoros prehispánicos, participar en la organización de nuevos museos nacionales y aprobar la exportación de tesoros asaltados, ofrecer discursos nacionalistas y participar en la repartija de los bienes históricos, publicar libros conmemorativos por el centenario patrio y refrendar normas que promovían el saqueo de las huacas.

Esto otorgó a las celebraciones oficiales organizadas por los miembros de la republica tradicional, que procedían de la línea de los antiguos saqueadores de tumbas prehispánicas, acciones contradictorias y contrapuestas, con hechos que iban en contra y en defensa de lo que hoy llamamos patrimonio cultural, presentando políticas públicas que nos remiten a lo que podría llamarse república saqueadora. Ello confirmó que cien años después de la independencia nacional quedaba aún pendiente la voluntad inicial de los libertadores en favor de los monumentos prehispánicos.

Mientras tanto, el santuario arqueológico de Pachacamac, símbolo inicial del saqueo perpetrado en tiempos de la conquista española, permanecía durante una década en manos de los saqueadores. Recién en 1931, pudo revocarse la autorización otorgada a Enrique Benavides para la búsqueda de tesoros en dicho lugar, impidiéndose de esa manera y por muchos años la realización de investigaciones arqueológicas y excursiones escolares y científicas en la huaca más importante de Lima, durante todo el triste oncenio de Leguía.

\section{Referencias bibliográficas}

Asensio, Raúl (2018). Los señores del pasado. Arqueólogos, museos y huaqueros en el Perú. Perú: Instituto de Estudios Peruanos.

Barreto, Carlos y De la Fuente, Germán (1926). Diccionario biográfico de figuras contemporáneas. Lima: Litografía y topografía T. Scheuch.

Basadre, Jorge (1963). Historia de la república del Perú. Lima: Ediciones historia.

Del Castillo, Luis Miguel y Moscoso, María (2002). El “chino" y el "indio": Pedro S. Zulén y Julio C. Tello, una amistad del novecientos a través de su correspondencia, 1914 - 1922. Arqueología y Sociedad, (14), 165-188.

Delibes, Rocío (2012). Desenterrando tesoros en el siglo XVI. Compañias de huaca y participación indígena en Trujillo del Perú. Madrid: Universidad de Sevilla, Consejo Superior de Investigaciones Científicas, Diputación de Sevilla.

Gänger, Stefanie (2019). Reliquias del pasado. El coleccionismo y el estudio de las antigüedades precolombinas en el Perú y Chile, 1837-1911. Lima: Instituto Francés de Estudios Andinos e Instituto Riva-Agüero.

Luque, Miguel (2012). Los libros de huacas en el virreinato del Perú: fiscalidad y control regio en torno a los tesoros prehispánicos enterrados. En Teresa Muñoz (Ed.), La monera: investigación numismática y fuentes archivísticas (pp. 293-311). Madrid: Asociación de Amigos del Archivo Histórico Nacional.

Menéndez, Luis Julio (1914). Memoria presentada por el Ministro de Justicia, Instrucción, Culto y Beneficencia. Doctor don Luis Julio Menéndez, al congreso ordinario de 1914. Lima: Ministerio de Justicia, Instrucción y Beneficencia.

Moreyra Paz Soldán, Manuel (1995). Estudios Históricos III. La moneda nacional y republicana. Lima: Pontifica Universidad Católica del Perú, Superintendencia de Banca y Seguros.

Mould de Pease, Mariana (2003). Machu Picchu y el Código de Ética de la Sociedad de Arqueología Americana: Una invitación al diálogo intercultural. Lima: Consejo Nacional de Ciencia y Tecnología y Pontificia Universidad Católica del Perú.

Muñoz Cabrejo, Fanni (2001). Diversiones públicas en Lima 1890-1920: la experiencia de la modernidad. Lima: Red para el Desarrollo de las Ciencias Sociales en el Perú.

Paz Soldán, Juan Pedro (1917). Diccionario biográfico de peruanos contemporáneo. Lima: Librería e imprenta Gil. 
Porras Barrenechea, Raúl. (1963). Fuentes históricas peruanas (Apuntes de un curso universitario). Lima: Instituto Raúl Porras Barrenechea, Universidad Nacional Mayor de San Marcos.

Porras Barrenechea, Raúl. (1974). Mito, tradición e historia del Perú. Lima: Peisa.

Quiroz, Francisco. (2014). Archivos, museos y enseñanza de la historia peruana en el siglo XIX. Cuadernos parlamentarios. Revista especializada del Centro de Capacitación y Estudios Parlamentarios, (10), 89-110.

Ravines, Rogger. (2006). Fuentes para la historia de la arqueología peruana. Boletín de Lima, revista científica y cultural, 18(105-106), 185-186.

Tantaleán, Henry. (2008). Las miradas andinas: arqueologías y nacionalismos en el Perú del siglo XX. Arqueología suramericana, 4(1), 34-52.

Tantaleán, Henry. (2016). Una historia de la arqueología peruana. Lima: Instituto de Estudios Peruanos.

Tantaleán, Henry y Cesar Astuhuamán. (Ed.) (2013). Historia de la arqueología en el Perú del siglo XX. Lima: Instituto Francés de Estudios Andinos.

Trazegnies, Fernando de. (1980). La idea de derecho en el Perú republicano del S. XIX. Lima: Fondo Editorial de la Pontificia Universidad Católica del Perú.

Urteaga, Horacio (1914). Bocetos históricos: estudios arqueológicos, tradicionales e histórico-critico. Lima: Casa Editora E. Rosay.

Washburn, Carlos A. (1908). Memoria presentada por el ministro de justicia, instrucción y culto Dr. D. Carlos A. Washburn al Congreso ordinario de 1908. Tomo II (Instrucción). Lima: Ministerio de Justicia, Instrucción y Culto

Zevallos, Jorge (1994). Huacas y huaqueros en Trujillo durante el virreinato, 1535-1835. Trujillo: Editora Normas Legales.

Presentado: 31/05/2020

Aceptado: 04/12/2020

Publicado online: 10/08/2021 